\title{
Studies on Mobility Indicators and the Effect of Congestion Reduction Measures on the Movement of Vehicular Traffic along G-6 Bus Route in Bangalore City using Micro Simulation Software
}

\author{
Harish H.S ${ }^{1}$ and Dr.Suresha S.N ${ }^{2}$ \\ ${ }^{1}$ Assistant Professor, Dept. of Civil Engineering, Jyothy Institute of Technology, Bangalore, India. \\ ${ }^{2}$ Assistant Professor, Dept. of Civil Engineering, National Institute of Technology Karnataka, Suratkal, India.
}

\begin{abstract}
Bangalore is one of the most important cities in India as it has rapid growth in the IT sector. As a direct result of rising population, the number of vehicles in the city has been increasing considerably. What adds to the traffic pressure in Bangalore is that there is very little scope for expansion of roads. This has led to massive congestion in the arterial roads of the city. The ill effects of congestion may reach highly undesirable proportions very rapidly. Traffic congestion is characterised by slower speeds, longer trip times, and increased queuing.

The main objective of the present study is to estimate the travel time and travel delay along the selected bus route i.e. BIG10 route number G6 - from Shantinagar bus stop (SNBS) to Kengeri satellite town bus stop (KSTBS) and analyse improvements to same through several congestion reduction measures using traffic micro simulation modelling and mobility indicators. The information and data necessary for making improvements in vehicular movement along this corridor is gathered together and considered. This data includes traffic volume data, road inventory data, travel times for various modes of travel and signal timings of all signalized intersections. The data so collected is used to simulate the vehicular flow using micro-simulation software. Changes with respect to road infrastructure, signal timings and various other possible solutions to reduce congestion is simulated and a cost benefit analysis is conducted.
\end{abstract}

Keywords: Transportation, Congestion, Travel time, Travel delay, VISSIM.

\section{Introduction}

Urban traffic congestion is widely recognized as one of the greater maladies of life in large cities. As such, most research effort has gone into devising measures for alleviating, or at least dealing with, this problem. An attempt to relieve congestion and decrease travel time through suitable measures is of high priority. It is widely recognized that the success of alleviating congestion depends on the quality and accuracy of the information provided. Congestion means continuous speed changes (decelerations and accelerations) and a low average speed in traffic flow. The speed changes cause the engines of vehicles to be continuously in a transient state. As a consequence many of the extra impacts in terms of fuel consumption and pollutant emissions are created by the congestion. Additionally, driving time, noise, etc. may increase remarkably depending on degree of congestion.

Also, it is very useful and important to know not only verbally, but in numeric amounts the congestion impacts. This becomes even more significant in a rapidly growing metropolitan city like Bangalore, where there is a steep increase in population over the past decade. The number of people living per square kilometre in the city has increased to 4,378 in 2011 from 2,985 in 2001, according to the census data released by Karnataka's directorate of census operations (Livemint, 2011) ${ }^{[1]}$.

\section{Review Of Literature}

The prominent traffic features in these developing countries are mixture of non motorised vehicles and motorised vehicles on road, which makes the task of analysis much more complex, due to the presence of heterogeneous traffic. This forms the basis for the need of equivalent passenger car units. The mixture of nmvehicles and m-vehicles makes serious decrease of the speed, and even causes traffic congestions (Gupta, $1986)^{[2]}$. The presence of bottlenecks is bound to reduce the speed of the vehicles and may also result in unnecessary delays in case of high traffic density. It was reported that the capacity of a two-lane road can drop by $28 \%$ when the lane width changed from 3.7 to $2.75 \mathrm{~m}$ (Stropher, 2004) ${ }^{[3]}$. It was also found out that, the conversion of a shoulder to an additional travel lane could be expected to increase the average speed of a twolane highway by about $5 \%$ for volumes exceeding 150 vehicles per hour. 
Another option is to provide importance to public transport vehicles by giving priority to buses, which considerably reduces the use of private vehicles (Khaled, 2006) ${ }^{[4]}$.

Thorough analysis about the impact of various congestion reduction strategies on the traffic performance (Liu, 2009) ${ }^{[5]}$ was conducted. Based on these studies and literature, different parameters were chosen which actually effect or contribute to the methodology and analysis of the present investigation.

\section{Research Methodology}

The methodology of the present investigation consists of EIGHT steps:

Step 1: In the selected BIG10 route (G6) leading into and out of the city, it is proposed to measure the quantum of vehicular movement at evenly spaced locations from point A to point B (say) at various times of the day, sampled over many days. Together, this survey will provide preliminary data to document the vehicular volume and broad patterns of flow during peak hour.

Step 2: Volume counts are taken manually at 6 major junctions both during peak and off-peak hours along the selected road stretch as shown in Fig.1 and the volume on the road is determined.

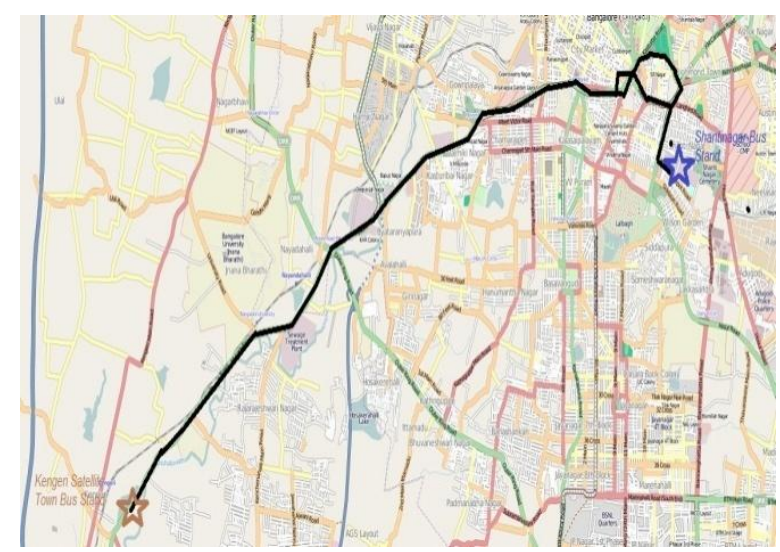

Fig.1: G-6 Bus Route.

Step 3: The road inventory data i.e. road features and road geometrics of the selected stretch which are noted down for the purpose of analysis are carriageway width, shoulder width, footpath, location name, bus stops, humps, potholes, junction.

Step 4: The travel times of different classes of vehicles are found by performing several trial runs along the G-6 route and their mean is tabulated. The journey starts at KST bus stop and ends at Shantinagar bus stop. Return journey from Shantinagar towards KST bus stop starts within fifteen minutes of reaching Shantinagar bus stop.

Step 5: The signal timings of all the major junctions are collected from Traffic Management Centre and also manually.

Step 6: All the collected data is then inputted into visualization and analysis platform, using simulation software \{it may be microscopic, mesoscopic or macroscopic modelling \} like VISSIM.

Step 7: The results are then evaluated through different mobility indicators like travel time index and congestion index. Various sections of the selected route will be differentiated using some parameters like distance from the origin, traffic congestion and street geometry.

Step 8: Cost benefit analysis is performed in order to assess the feasibility and value of congestion reduction measures.

\section{Data Collection}

The data collection process when conducted in an orderly manner ensures that data gathered is both defined and accurate. The collected data provides a baseline for further analysis. The processes involved in data collection required for the analysis of travel times and travel delays are traffic volume studies, road inventory studies, travel times for various modes of travel, signal timings of all major junctions.

Traffic volume studies are conducted to determine the number, movements, and classifications of roadway vehicles at a given location. Six major locations where the traffic volume survey was conducted are:

A) Near RV college

B) Rajarajeshwari Nagar Junction

C) BHEL Junction

D) Near TOTAL mall

E) Town hall Junction

F) Double Road Junction 
Traffic volume data is collected near all the major junctions along this route and later converted to equivalent passenger car units as shown in Table 1 using IRC 106-1990.

TABLE 1: EQUIVALENT PASSENGER CAR UNITS

\begin{tabular}{|c|l|c|c|}
\hline \multirow{2}{*}{ Sl. No. } & \multirow{2}{*}{$\begin{array}{c}\text { Vehicle } \\
\text { Type }\end{array}$} & $\begin{array}{c}\text { Equivalent PCU Factors } \\
\text { \% composition of Vehicle } \\
\text { type in Traffic Stream }\end{array}$ \\
\cline { 3 - 4 } & & $\mathbf{5 \%}$ & $>\mathbf{1 0 \%}$ \\
\hline 1 & 2-Wheelers & 0.5 & 0.8 \\
\hline 2 & Car & 1.0 & 1.0 \\
\hline 3 & Auto & 1.2 & 2.0 \\
\hline 4 & LCV & 1.4 & 2.0 \\
\hline 5 & Truck/Bus & 2.2 & 3.7 \\
\hline 6 & Tractor & 4.0 & 5.0 \\
\hline
\end{tabular}

Reconnaissance Survey was carried out along the Corridor and at the Junctions and the physical characteristics of the corridor and junctions such as road geometrics, pavement details, traffic Controls (signs, signals, road markings and parking restrictions), sidewalks, shoulders, adjacent land use were observed.

Along the G-6 route (From Shantinagar Bus Stand TO Kengeri Satellite Town Bus Stop), for every 250 meters, the road parameters like carriageway width(See Fig.4.14), shoulder width, footpath, location name, bus stops, humps, potholes, junction were noted down.

The travel times of various modes of travel like two wheeler, three wheeler, cars and buses were obtained by performing several trial runs along the G-6 route. The journey started at KST bus stop and ends at Shantinagar bus stop. Return journey from Shantinagar towards KST bus stop started within fifteen minutes of reaching Shantinagar bus stop.

Three trials were conducted for each category as explained in section 3 of the present investigation and their mean was calculated.

The signal timings of major junctions along G-6 bus route in Bangalore city are collected from Traffic Management Centre and also manually. The signal timings of all the major junctions along G-6 bus route in Bangalore city are shown in Table 4.

\section{Results and Analysis}

Some indicators of congestion that confirm the congestion trend in G-6 bus route in Bangalore City are travel time index and congestion index given by:

Travel Time Index $=$ Actual Travel Time/Ideal (free flow) Travel Time

Congestion index $=1-(\mathrm{A} / \mathrm{M})$

Where,

M: Desirable ideal average journey speed on major road networks of a city during peak hour, which is assumed as $40 \mathrm{KMPH}$ as per DULT (Directorate of Urban Land Transport, Karnataka) standards set in the year 2009.

A: Average journey speed observed on major corridors of the city during peak period.

In ideal condition congestion index is zero. The congestion index at Kalingrao Junction and Satellite bus stop junction were found to be most congested places having a congestion index of 0.82 and 0.79 respectively as shown in figure 2 .

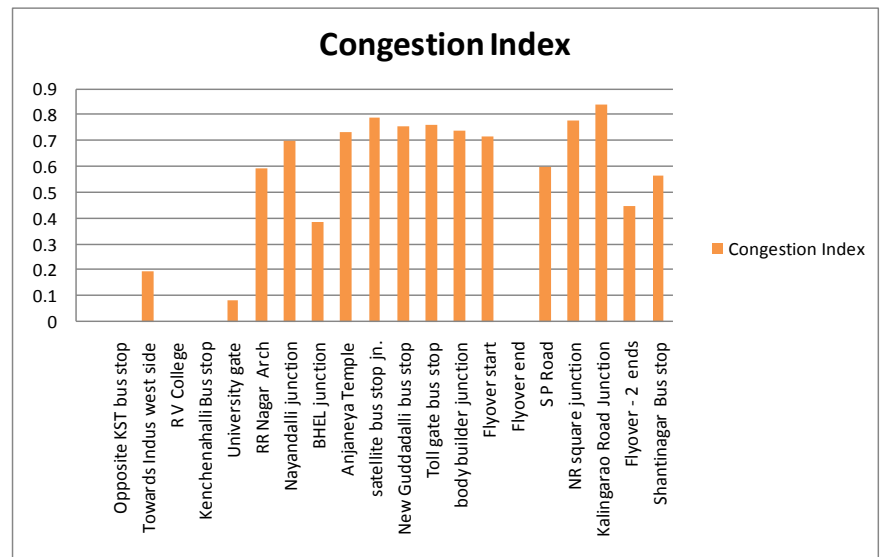

Fig. 2: Congestion Index (From KSTBS to SNBS) 
For micro-simulation analysis, a do-nothing model is developed by inputting all the collected data into the traffic micro-simulation software VISSIM. After calculating cumulative hourly volume of vehicles, the peak hour, where the flow of vehicles is maximum is considered for evaluation. This is done to test whether VISSIM validates the travel times that was collected in the field. The basic data required as inputs for the preparation of a traffic simulation model using VISSIM are number of vehicles, classes of vehicles, number of lanes, width of the carriageway, signal cycle time.

The savings in travel time by the application of these congestion reduction measures is also evaluated using benefit cost analysis. The objective is to obtain insights regarding the effects of varying the existing conditions by providing suitable traffic improvement measures using micro simulation modelling and also analyse the viability of these measures. Using IRC: SP: 30-2009 (Manual for Economic evaluation of Highway Projects in India) and traffic volume data, the benefits of taking up these infrastructure improvement measures can be quantified through cost saved per minute.

Approximate cost required to implement different congestion reduction measures are shown in Table 2. The cost required to modify the signal timings is comparatively very low. The travel times observed using VISSIM traffic simulator and the savings in time by adopting congestion mitigation measures and the corresponding savings in cost are presented in Table 3.

TABLE 2: COST FOR IMPLEMENTING MEASURES

\begin{tabular}{|l|l|c|}
\hline SI & \multicolumn{1}{|c|}{ Congestion reduction measure } & $\begin{array}{c}\text { Approx. Amount } \\
\text { Spent in Cr.(Rs.) }\end{array}$ \\
\hline 1 & Road Widening (3.7 Kms) & 3.37 \\
\hline 2 & Providing Junction free corridors & \\
\hline & a)Chord Road to Mysore road $(500 \mathrm{~m})$ & 25.62 \\
\hline & b)Nayandalli Grade Separator(750 m) & 38.43 \\
\hline & c)NR Square Junction(600 m) & 30.75 \\
\hline 3 & Combination of Junction free corridors & 94.81 \\
\hline 4 & $\begin{array}{l}\text { Flyover from Sirsi Circle to BU gate }(10 \\
\text { Kms) }\end{array}$ & 512.5 \\
\hline
\end{tabular}

Note: The above costs exclude land acquisition costs.

\begin{tabular}{|c|c|c|c|c|c|}
\hline \multirow{2}{*}{ Sl } & \multirow[b]{2}{*}{ Model Type } & \multicolumn{2}{|c|}{ Time in minutes } & \multicolumn{2}{|c|}{ Savings in Time(min.) } \\
\hline & & $\begin{array}{c}\text { From } \\
\text { KSTBS }\end{array}$ & $\begin{array}{l}\text { From } \\
\text { SNBS }\end{array}$ & \multirow{2}{*}{$\begin{array}{c}\text { From } \\
\text { KSTBS }\end{array}$} & \multirow{2}{*}{$\begin{array}{l}\text { From } \\
\text { SNBS }\end{array}$} \\
\hline 1 & Basic Model & 54.42 & 54.98 & & \\
\hline 2 & Road Widening & 46.98 & 43.62 & 7.43 & 11.37 \\
\hline 3 & $\begin{array}{l}\text { Change in Signal } \\
\text { Timings }\end{array}$ & 47.78 & 54.10 & 6.63 & 0.88 \\
\hline 4 & $\begin{array}{l}\text { Flyover } \\
\text { (Sirsi circle to } \\
\text { BU gate) }\end{array}$ & 41.65 & 39.95 & 12.77 & 15.03 \\
\hline 5 & $\begin{array}{l}\text { Removal of } \\
\text { Humps and } \\
\text { potholes }\end{array}$ & 47.25 & 45.25 & 7.17 & 9.73 \\
\hline 6 & $\begin{array}{l}\text { Junction free } \\
\text { corridors }\end{array}$ & 47.00 & 48.10 & 7.42 & 6.88 \\
\hline 7 & $2,3,5 \& 6$ & 35.83 & 38.47 & 18.58 & 16.52 \\
\hline 8 & $2,3 \& 5$ & 42.73 & 41.12 & 11.68 & 13.87 \\
\hline
\end{tabular}

\section{Conclusions}

The present study used mobility indicators as a criterion to establish massive delays of vehicles and microscopic simulation technology was used as a tool to evaluate the congestion mitigation measures, i.e. Removal of Bottlenecks and Road widening, Modification and offsetting of Signal Time, Removal of Humps and Potholes, Junction free corridors and also combined measures.

By calculating cumulative hourly volume of vehicles, it is safe to state that, the peak hour volume along this corridor cannot be associated with a particular time. This gives a clear indication that, this is a very busy route. The present investigation deals with evaluating congestion reduction measures through time bound analysis. Also, the cost analysis gives an insight into the feasibility of applying such measures for the betterment of traffic scenario. The upgrading and improvement of existing conditions will invariably reduce travel time as 
well as improving the reliability of transport services. Travel delays are given due importance during analysis, because, for road users, time has some connection with money. This is substantiated using the benefit cost analysis. Cost benefit analysis is used to assess of whether a proposed project or process is worth doing.

The travel time results obtained from VISSIM traffic simulation software is then comparatively analysed. Although, the degree of correlation between time and money depends primarily on the manner in which the opportunities made possible by the increased availability of time are utilised.

Addressing the range of congestion problems and the reduction measures with the greatest benefit for the least cost recognizes the diversity of the problem and advantages of each congestion reduction option.

From Table 2 and Table 3, feasible options for congestion reduction measures and the corresponding savings in terms of travel time are obtained.

\section{Recommendations}

These findings suggest several courses of action for the reduction in congestion. An implication of these findings is that both cost and benefits is taken into account when the feasibility of these congestion reduction measures is being analysed. The average congestion index for route under study is greater than 0.7 , which is very much on the higher side. There is, therefore, a definite need for a number of changes which need to be made to relieve congestion. These changes which were made using VISSIM micro simulation software, gave the results in terms of reduction in travel times. Alternatives like extension of Sirsi circle flyover to Bangalore University gate is not a feasible option as the cost required to construct the same is very high and the corresponding benefits in terms of reduction in travel time and money spent is not proportional. This was clearly analysed through benefit cost analysis along with other congestion mitigation measures. The reasonable options to tackle this issue of congestion could be to incorporate certain changes like modification and offsetting of signal timings, road widening at certain problematic junctions, making the junction free roads wherever possible, removal of unnecessary speed breakers and improving road surface conditions by filling potholes along this route.

VISSIM is a program with abilities to display and visualize complex traffic flow in a graphical way. But, it has its share of limitations (Nedal, 2009) ${ }^{[6]}$ like the link numbers which decides the overlap order of the links cannot be changed and the delays are not calculated for the queues extending beyond the model. However, users cannot deny that some functions and interface provided by VISSIM has made the modelling of road networks more user friendly.

\section{Future Scope}

This study is an initial work and opens the door for several future studies. In the future, further research might explore more strategies, such as congestion pricing, could be evaluated using the micro simulation tool. Scenarios with different incident locations could also be tested. Finally, dynamic demand and various incident occurrence times could be examined.

\section{Acknowledgement}

The satisfaction and euphoria that accompany the successful completion of any task would be incomplete without mentioning the people who made it possible, whose constant guidance and encouragement crowned my efforts with success. I wish to express my deep sense of gratitude to Prof.T.G.Sitharam (Chairman, CiSTUP, IISc, Bangalore) and Dr.Deepak Baindur for their able guidance and useful suggestions, which helped me in completing this research paper.

\section{References}

[1] Livemint, Livemint.com (2011). "Karnataka population growth slows, Bangalore gets more crowded", retrieved on 09-08-2011 from http://www.livemint.com/2011/04/06233223/Karnataka-population-growth-sl

[2] Gupta, A.K., and Khanna, S.K. (1986). "Mixed traffic flow analysis for developing countries", World Congress on Transport Research, pp. 1521-1534.

[3] Stropher, R., (2004). "Reducing road congestion: a reality check", Journal of transport policy, Vol.11, No. 4, pp.117-131.

[4] Khaled, F.A., Ahmed, F.A., Hani, S.M., and Akmal, S.A. (2006). "Modelling Bus Priority Using Intermodal Dynamic Network Assignment-Simulation Methodology "Journal of Public Transportation, Vol. 9, No. 5,.pp.1-22.

[5] Liu, Z., Chunyan, L., Li, C. (2009). "Traffic impact analysis of congestion charge in mega cities "Journal of Transportation Systems Engineering and Information Technology" Vol. 9, No. 6, pp.123-142

[6] Nedal, T. R., and Rahman, S. M. (2009). "A comparative analysis of currently used microscopic and macroscopic traffic simulation software", The Arabian Journal for Science and Engineering, Vol. 34, No. 1B, pp. 121-134. 